\title{
Cross-shelf benthic community structure on the Great Barrier Reef: relationships between macroalgal cover and herbivore biomass
}

\author{
Sharon Wismer, Andrew S. Hoey, David R. Bellwood* \\ Australian Research Council Centre of Excellence for Coral Reef Studies, and School of Marine and Tropical Biology, \\ James Cook University, Townsville, Queensland 4811, Australia
}

\begin{abstract}
The Great Barrier Reef (GBR) is one of the most extensively studied coral reef systems in the world, yet to date, there has been no comprehensive multi-spatial scale evaluation of its benthic community structure. Such descriptions provide a useful reference point for evaluating future community changes. Moreover, large-scale associations between macroalgae and herbivory on the GBR are yet to be investigated. Our aim, therefore, was to quantify all major substratum categories across multiple spatial scales and investigate cross-shelf relationships between macroalgal cover and herbivore biomass. Using point-intercept transects and timed underwater censuses, individual benthic components and roving herbivorous fish densities were quantified across 3 spatial scales: latitude, continental shelf position and within-reef habitat. Principal component analysis and analysis of similarities (ANOSIM) revealed a distinct separation of inner-shelf reef habitats from all mid- and outer-shelf habitats in both northern and central regions of the GBR. Macroalgal cover was generally high on inner-shelf reefs (36 to $66 \%$ ) and decreased markedly on all mid- and outer-shelf habitats ( 0 to $15 \%$ ). A significant negative correlation was found between macroalgal cover and total herbivorous fish biomass, but no relationship was found between macroalgal cover and macroalgal browser biomass. In contrast to macroalgae, the cover of crustose coralline algae and live scleractinian corals increased markedly across the shelf in both regions of the GBR. These patterns appear to be shaped by both physical and biological factors, including wave energy, sedimentation and grazing intensity.
\end{abstract}

KEY WORDS: Benthic community structure $\cdot$ Macroalgae $\cdot$ Phase shift $\cdot$ Herbivory $\cdot$ Coral reef · Baseline Resale or republication not permitted without written consent of the publisher

\section{INTRODUCTION}

Changes in the benthic community composition of coral reefs have been well documented worldwide (Done 1992, Gardner et al. 2003, Wilkinson 2004). This is particularly true for Caribbean, Hawaiian and east African reefs, where large-scale phase shifts from coral to macroalgal dominance have occurred (Hughes 1994, Hunter \& Evans 1995, Shulman \& Robertson 1996, McClanahan et al. 2001, Graham et al. 2006, Ledlie et al. 2007). Although phase or regime shifts refer to reefs changing to an alternate state, they are often marked by a decrease in the cover of live coral and an increase in the cover of erect macroalgae (i.e. leathery or foiliose algae, sensu Steneck 1988) (Done 1992, Hughes 1994, McCook 1999). This transition to macroalgal dominance is widely regarded as a degraded state for a coral reef (Done 1992, McCook 1999, Hughes et al. 2003, Bellwood et al. 2004, Mumby et al. 2006) and can be related to a combination of factors, including storms, climate change, reduced herbivory and/or increased input of land-based nutrients (Smith et al. 1981, McCook 1999, Hughes et al. 2003). However, the question still remains as to how much macroalgae within a reef can be regarded as 'normal', and if macroalgal dominance is invariably associated with reef degradation.

Whilst there may be no pristine reefs in the world (Pandolfi et al. 2003), healthy reefs are commonly characterized as systems that are not adversely affected by anthropogenic disturbances and retain a high cover of live coral and relatively low abundances of macroalgae 
(Done 1992, Hughes et al. 2003, Bellwood et al. 2004). Nevertheless, it has been argued that reefs can also be dominated by macroalgae and still be considered healthy with all essential ecological processes intact. For instance, some reefs of the Northwestern Hawaiian Islands are largely dominated by turf and fleshy macroalgae (Vroom et al. 2005, 2006). Their isolation and subsequent limited anthropogenic disturbance suggest that this may represent the 'natural' state of these reefs.

Within the Great Barrier Reef (GBR), which is widely regarded as the world's most intact coral reef system (Pandolfi et al. 2003, Bellwood et al. 2004, Wilkinson 2004), macroalgae (particularly Sargassum) have frequently been reported from inshore reefs (e.g. Done 1992, Martin-Smith 1993, McCook et al. 1997). Despite this, there is still a lack of quantitative data on both the distribution and abundance of macroalgae within the GBR (McCook et al. 1997). Previous studies have provided detailed descriptive data on the distribution patterns of other substratum categories, including scleractinian corals (Done 1982), soft corals (Dinesen 1983) and crustose coralline algae (Fabricius \& De'ath 2001). However, there have been no comprehensive crossshelf evaluations of the benthic community structure of the GBR published that include all major benthic substratum groups, including macroalgae, across multiple spatial scales. Such data are critical, as they serve as a baseline for evaluating future community changes in both abundance and distribution of various benthic components. Furthermore, they lay the foundation for exploring the relationship between benthic community structure and critical functional groups across a range of spatial scales.

Much previous research has focused on determining how various ecosystem processes influence or modify the composition of selected components of benthic communities. As a result, a range of physical and biological mechanisms have been identified that may shape the benthic community structure of coral reefs, including herbivory (e.g. Bellwood et al. 2006, Hughes et al. 2007), eutrophication (e.g. Smith et al. 1981, Littler et al. 2006) and physical disturbances, such as wave energy and storms (e.g. Madin \& Connolly 2006). Of these mechanisms, herbivory is widely regarded as a key determinant of benthic communities on coral reefs (e.g. McCook 1999, Burkepile \& Hay 2006). Indeed, the system-wide removal of herbivores has underpinned shifts to macroalgal dominance on Caribbean (Hughes 1994), Hawaiian (Hunter \& Evans 1995) and east African reefs (McClanahan et al. 2001). The exclusion of herbivores has also induced a shift to macroalgal dominance on the GBR (Hughes et al. 2007). Such relationships are supported by models of algal succession, which predict that a reduction in grazing intensity will lead to a shift from grazing-resistant crustose coralline algae and highly productive turf algae to less productive erect macroalgae (e.g. Sargassum, Turbinaria, Padina) (Steneck 1988, Littler et al. 2006). Therefore, one would expect to find strong negative relationships between herbivore biomass and macroalgal cover, as reported in Hawaiian (e.g. Friedlander et al. 2007) and Caribbean (e.g. Williams \& Polunin 2001) systems. However, on the GBR, such associations are yet to be evaluated across large spatial scales.

The primary aims of the present study, therefore, were to (1) provide a comprehensive overview of the benthic community structure of the GBR by quantifying the distribution patterns of all major benthic substratum categories across 3 spatial scales (latitude, shelf and habitat), and (2) quantify the herbivorous fish communities in order to examine the relationship between herbivory and macroalgal cover across the GBR.

\section{MATERIALS AND METHODS}

Benthic surveys. Surveys were conducted within 2 regions of the GBR: (1) the northern region (approx. $14^{\circ} 40^{\prime} \mathrm{S}$ ) in December 2004 and (2) the central region (approx. $18^{\circ} 47^{\prime} \mathrm{S}$ ) in June and October 2005. In each region, 2 reefs were censused within each of the 3 cross-shelf locations: inner-, mid- and outer-shelf (Fig. 1). Within the northern region, 2 islands within the Turtle Group (11 to $15 \mathrm{~km}$ from the mainland) were selected as inner-shelf reefs; MacGillivray Reef and Lizard Island (28 to $35 \mathrm{~km}$ ) as mid-shelf reefs; and Day Reef and Hicks Reef (48 to $53 \mathrm{~km}$ ) as outer-shelf reefs. Central region reefs consisted of Pandora Reef and Havannah Island (16 to $23 \mathrm{~km}$; inner-shelf); Wheeler Reef and Davies Reef (55 to $62 \mathrm{~km}$; mid-shelf); and Dip Reef and Bowl Reef (87 to 98 km; outer-shelf).

Within each of the 12 reefs, 3 to 4 habitats were surveyed, consisting of the back reef, reef flat, crest and slope (defined in Bellwood \& Wainwright 2001). Due to the lack of a clearly defined reef crest on the innershelf reefs, the entire seaward slope within these reefs was censused as the slope/crest (following Bellwood \& Wainwright 2001). In each habitat on each reef, 12 replicate $10 \mathrm{~m}$ transects were censused. Transects were haphazardly placed within each habitat and, where possible, laid parallel to the reef crest. The type of substratum immediately under and $1 \mathrm{~m}$ to either side of the transect tape was recorded at $1 \mathrm{~m}$ intervals along the transect, following Bellwood (1995), giving a total of 33 points per transect. Substratum categories were identified as macroalgae $(>10 \mathrm{~mm}$ in height; this includes foiliose and leathery algae, e.g. Sargassum, and species $>10 \mathrm{~mm}$ in height in the epilithic algal 

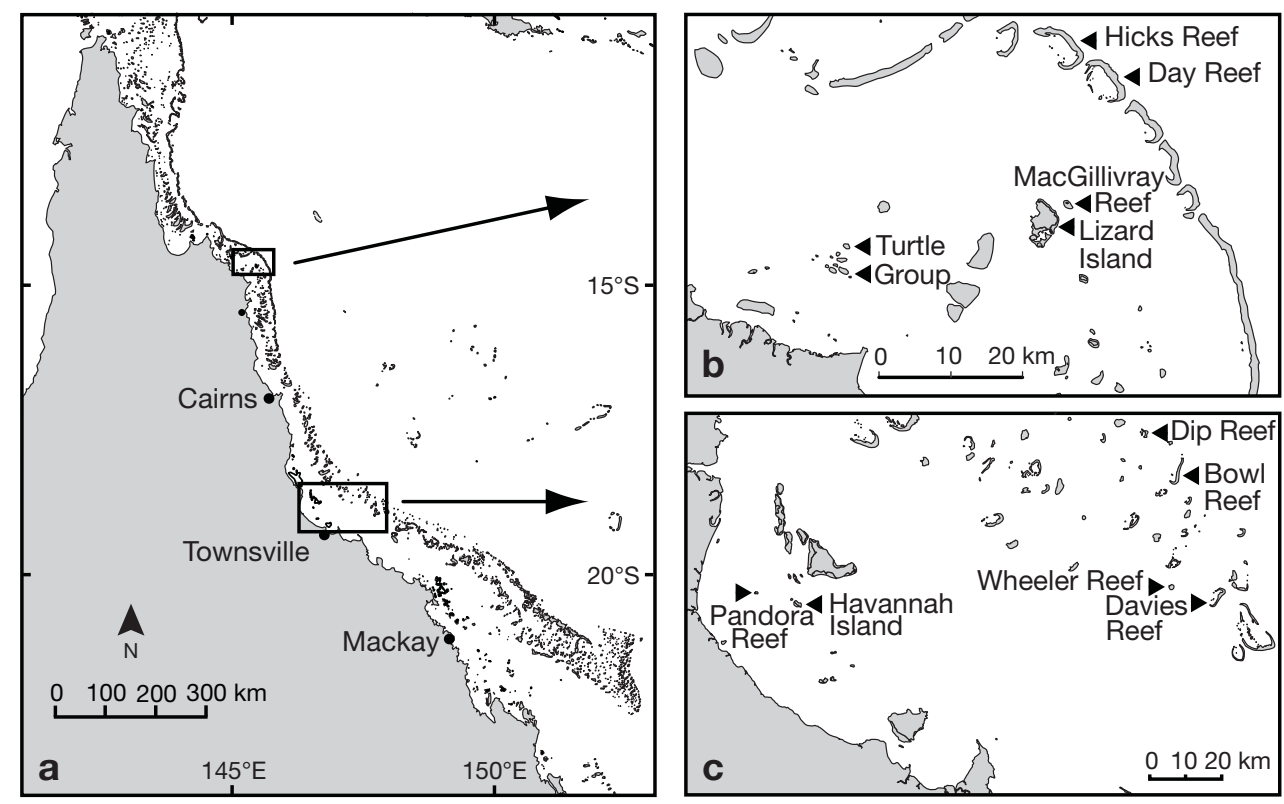

Fig. 1. Great Barrier Reef (GBR). (a) Geographic locations of the 2 regions censused. (b) Cross-shelf census sites in the northern GBR showing inner-shelf (Turtle Group), mid-shelf (Lizard Island and MacGillivray Reef) and outer-shelf reefs (Hicks and Day Reefs). (c) Cross-shelf census sites in the central GBR showing inner-shelf (Pandora Reef and Havannah Island), mid-shelf (Wheeler and Davies Reefs) and outer-shelf reefs (Dip and Bowl Reefs)

matrix); epilithic algal matrix (EAM; sensu Wilson et al. 2003, $\leq 10 \mathrm{~mm}$ in height); crustose coralline algae (CCA); live scleractinian coral; damselfish territory (marked by long epilithic algae defended by a damselfish); dead coral; and sand/rubble. Sponges, soft corals, bryozoans and ascidians were grouped as 'other' due to their low abundances (mean cover = $4.1 \%$ across all habitats).

Herbivore censuses. A series of timed swims were used to quantify the herbivorous fish communities in each habitat, reef, shelf location and region. Fish censuses were conducted at the same time and in the same area as the benthic transects. A comparable hierarchical sampling design was used, but with four $10 \mathrm{~min}$ timed swims in each habitat. Each timed swim census consisted of 2 divers swimming parallel to the reef crest, recording all nominal roving herbivorous fishes (Acanthuridae, Siganidae, Labridae, Kyphosidae and Ephippidae). The first diver recorded individuals greater than $10 \mathrm{~cm}$ in total length (TL) in a $5 \mathrm{~m}$ wide transect. The second diver followed $5 \mathrm{~m}$ behind and recorded all individuals less than $10 \mathrm{~cm}$ TL in a $1 \mathrm{~m}$ wide transect. All fish were identified to species, and their total length estimated in $5 \mathrm{~cm}$ size categories. Kyphosus cinerascens, K. vaigiensis, Naso brachycentron, N. lituratus, N. tonganus, N. unicornis, Siganus canaliculatus and Platax pinnatus were identified as macroalgal browsers (species known to feed on fleshy macroalgae, following Randall et al. 1997, Choat et al.
2002, Bellwood et al. 2006, Fox \& Bellwood 2008, Cvitanovic \& Bellwood 2009). Previously calibrated distances were used to estimate transect lengths and convert densities per unit effort to densities per unit area (following Bellwood \& Wainwright 2001), while density estimates were converted to biomass using published length-weight relationships (Kulbicki et al. 1993, 2005).

Data analysis. Principal component analysis (PCA) was used to investigate variation in benthic community composition between the 2 regions of the GBR, and among shelf positions and reef habitats. This analysis was based on the mean proportion of each substratum type in each habitat within each shelf location (a mean of 24 transects per habitat), giving a total of 22 'sites' (2 regions, 3 shelf positions, 3 to 4 habitats per shelf position). The analysis was based on the covariance matrix of the proportion data. To provide an objective description of the 'site' groupings, a Ward's method hierarchical cluster analysis was undertaken based on the squared Euclidean distances of the proportion data. Additionally, a 1-way analysis of similarity (ANOSIM) was performed to determine whether the benthic community composition differed significantly among shelf locations.

A series of 3-way ANOVAs were performed to determine the effect of region, shelf location and habitat on each of the benthic substratum categories. Type IV sums of squares (SS) were used to adjust for the lack of 
a fourth habitat on inner-shelf reefs. Assumptions of the ANOVA were examined by residual analysis. Macroalgae, CCA and sand/rubble were square-root transformed, dead coral was cube-root transformed, and EAM, live coral and 'other' were arcsine transformed to improve normality and homoscedasticity. Bonferroni correction was used to allow for the multiple comparisons.

Cross-shelf relationships between macroalgal cover and herbivore biomass (total herbivorous fish and macroalgal browsing fish biomass) were investigated using a series of bivariate correlations. These analyses investigated the overall cross-shelf relationships between the variables, with values based on the mean proportion of macroalgae and the mean biomass of herbivorous fishes for each habitat on each reef, for both the northern and central GBR. Data were logtransformed prior to analysis to improve linearity.

\section{RESULTS}

\section{Cross-shelf community patterns}

The PCA showed clear cross-shelf variation in benthic community structure, with the first 2 components explaining $76.6 \%$ of the total variation ( 49.7 and $26.9 \%$ respectively) (Fig. 2). Inner-shelf reef habitats were separated from all mid- and outer-shelf reef habitats along the first principal component and were characterized by a high proportion of macroalgae (Fig. 2). This separation was supported by the cluster analysis. Moreover, ANOSIM indicated moderate differences in benthic community composition between inner- and mid-shelf reef habitats $(R=0.625, p=0.001)$ and innerand outer-shelf reef habitats $(\mathrm{R}=0.563, \mathrm{p}=0.002)$, but no differences between mid- and outer-shelf reef habitats $(\mathrm{R}=-0.024, \mathrm{p}=0.531)$, reflecting the groupings in the ordination analysis. The only outlier to this general pattern was the inner-shelf back reef habitat in the northern region, which clustered with the mid- and outer-shelf habitats (Fig. 2a). This was driven by a relatively large proportion of live coral and limited macroalgae in this location (Fig. 2b). This was the true reflection of the habitat, which was characterized by numerous large Porites bommies and branching Acropora stands.

The benthic structure of mid- and outer-shelf reef 'sites' exhibited greater similarity in benthic composition among reef habitats than shelf position or region (Fig. 2a). The reef flat and back reef habitats of mid- and outer-shelf reefs in both regions were characterized by a relatively higher cover of EAM and sand/rubble. In contrast, northern outer-shelf and central mid- and outershelf reef crest habitats, northern outer-shelf reef slope and central mid-shelf reef slope were all characterized by a higher proportion of live coral and, to a lesser extent, CCA (Fig. 2b).

\section{Spatial distribution of individual substratum categories}

The distribution of all substratum categories was influenced by an interaction between region, shelf location and habitat: macroalgae $\left(F_{5,516}=9.67, \mathrm{p}<0.001\right)$,

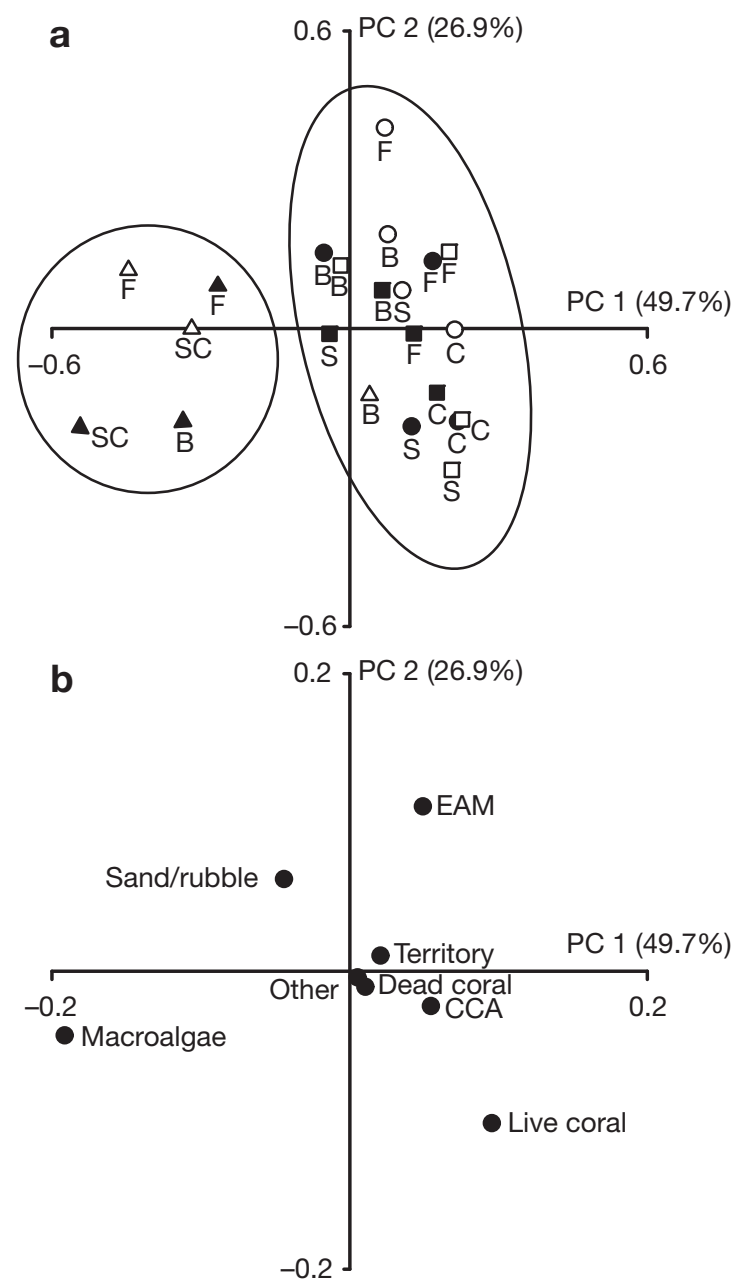

Fig. 2. Principal component analysis showing the relationship between the benthic community structure at 22 'sites' across 2 regions of the GBR. (a) Ordination plot showing the relationship between sites. Each site is based on 12 transects per habitat on each of 2 reefs in each shelf location (24 transects in total). Ellipses: groupings identified by the cluster analysis; triangles: inner-shelf sites; circles: mid-shelf sites; squares: outer-shelf sites; open symbols: northern GBR; solid symbols: central GBR habitats. B: back reef; F: reef flat; C: reef crest; S: reef slope. (b) Substratum category loadings showing the relative contributions of each substratum to the observed differences in benthic community structure. CCA: crustose coralline algae; EAM: epilithic algal mix 
$\operatorname{EAM}\left(F_{5,516}=13.95, \mathrm{p}<0.001\right), \operatorname{CCA}\left(F_{5,516}=5.46, \mathrm{p}<\right.$ $0.001)$, live coral $\left(F_{5,516}=20.18, \mathrm{p}<0.001\right)$, sand $/$ rubble $\left(F_{5,516}=18.54, \mathrm{p}<0.001\right)$, damselfish territory $\left(F_{5,516}=\right.$ 15.49, $\mathrm{p}<0.001)$, dead coral $\left(F_{5,516}=15.52, \mathrm{p}<0.001\right)$ and 'other' $\left(F_{5,516}=8.47, \mathrm{p}<0.001\right)$. This interaction makes interpretation difficult. Data are therefore summarized graphically and each category examined separately below. Further details of the ANOVA results are provided in Table A1 in Appendix 1 (see www.intres.com/articles/suppl/m376p045_app.pdf.

There was considerable cross-shelf variation in the cover of macroalgae across the GBR, although the northern and central regions exhibited broadly similar trends. Macroalgal cover was greatest on inner-shelf reefs and decreased markedly on mid- and outer-shelf reefs in both regions of the GBR (Fig. 3a). Of the 264 transects in each region, macroalgae was the dominant category in 18.1 and $25.7 \%$ of transects, attained $50 \%$ or higher cover in 11.1 and $18.2 \%$ of transects and exceeded live coral cover in 23.3 and $32.9 \%$ of transects (values in the northern and central GBR respectively). On northern inner-shelf reefs, macroalgal cover was greatest on the reef flat $(50.0 \%)$ and decreased on slope/crest (40.1\%) and back reef habitats (16.0\%). In contrast, on central inner-shelf reefs, the reef flat had the lowest macroalgal cover (36.2\%) and back reef $(48.9 \%)$ and slope/crest $(66.2 \%)$ habitats the highest (Fig. 3a). Macroalgal cover was extremely low on all northern mid- and outer-shelf reef habitats, ranging from 0 to $0.9 \%$ (Fig. 3a), but was slightly higher on central mid- and outer-shelf reefs, ranging from $1.7 \%$ on the reef crest of mid-shelf reefs to $15.4 \%$ on the outershelf reef slope (Fig. 3a). Macroalgae in both northern and central inner-shelf reefs were dominated by Ochrophyta (Phaeophyceae; predominantly Sargassum, Padina and Turbinaria), and to a lesser extent Rhodophyta (Laurencia, Galaxaura and Hypnea). In contrast, Chlorophyta (predominantly Caulerpa, Halimeda and Chlorodesmis) was the only type of macroalga recorded in central mid- and outer-shelf reefs.

In both regions of the GBR, live coral cover was the greatest on mid- and outer-shelf reefs, yet there was considerable variation amongst habitats within each shelf location. In northern and central mid- and outershelf reefs, live coral cover generally increased from sheltered to more exposed habitats, ranging from $12.0-26.6 \%$ on the back reef and $7.6-29.0 \%$ on the reef flat to $41.3-43.0 \%$ on the reef crest and 20.5-49.3\% on the reef slope (Fig. 3b). In contrast, on northern and central inner-shelf reefs, live coral cover was the greatest on the back reef (26.9-41.8\%) and decreased to $15.0-15.3 \%$ on the slope/crest and $1.1-8.0 \%$ on the reef flat (Fig. 3b).

CCA were most abundant on the outer-shelf reef habitats in the northern GBR and the mid- and outer- shelf reef habitats in the central GBR (Fig. 3c). With the exception of the reef flat of central inner-shelf reefs $(10.1 \%)$, CCA cover on inner-shelf reefs was consistently low for both regions of the GBR, ranging from $0.2-1.5 \%$ (Fig. 3c).

For both regions of the GBR, the cover of EAM was generally greatest on mid-shelf reefs and lowest on inner-shelf reefs, with the highest cover occurring on the reef flat within each shelf position (Fig. A1 in Appendix 1). Unlike most other substrata, sand/rubble showed no clear cross-shelf patterns. However, within reefs, the cover of sand/rubble tended to be lowest on

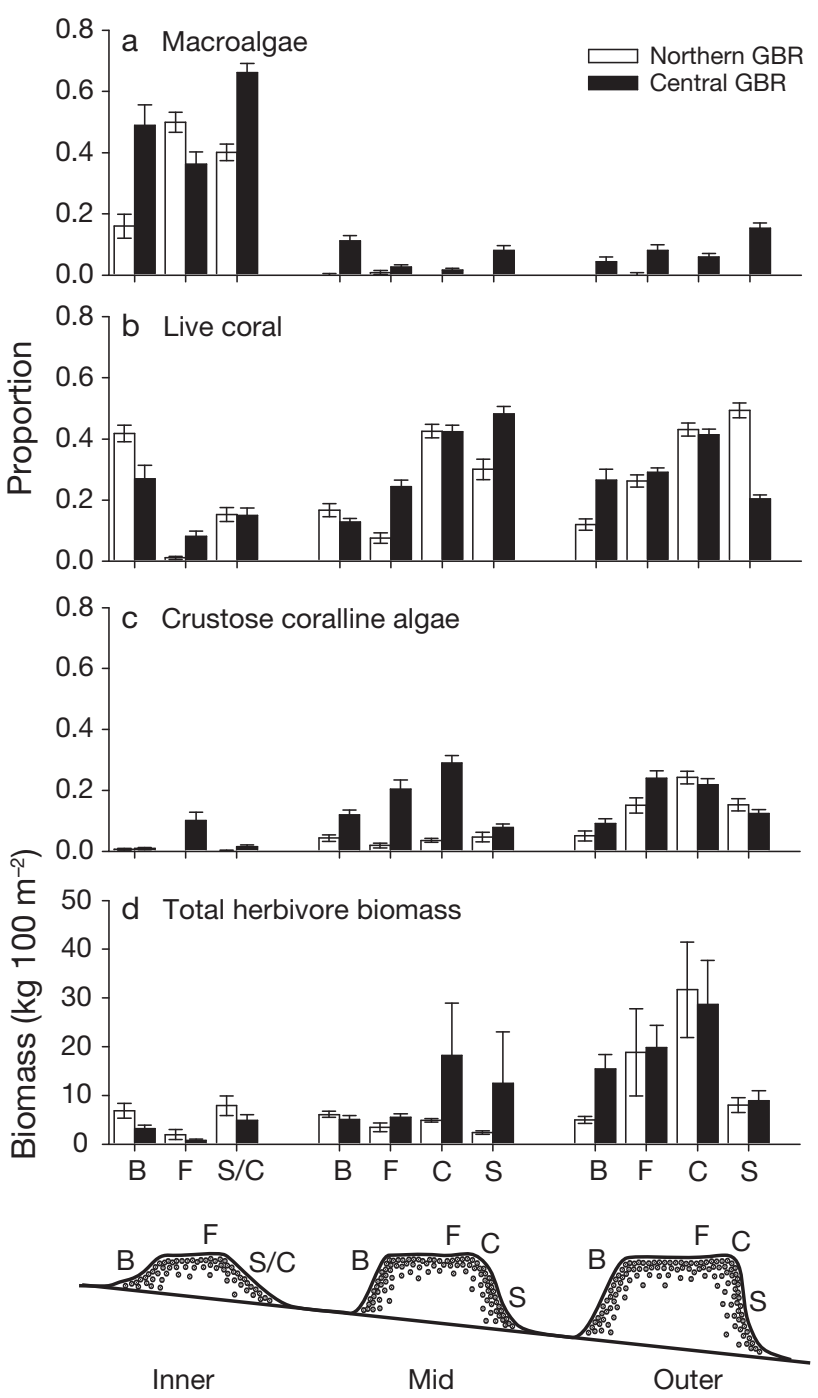

Fig. 3. Cross-shelf variation in the cover of 3 benthic categories and herbivorous fish biomass (mean $\pm \mathrm{SE}$ ) within the northern and central regions of the GBR: (a) macroalgae, (b) live scleractinian coral, (c) crustose coralline algae, (d) total herbivore biomass. Each mean is based on 12 benthic transects from each of 2 reefs $(n=24)$ or 4 timed underwater censuses from each of 2 reefs $(n=8)$. Habitats: B: back reef; F: reef flat; C: reef crest; S: reef slope. Continental shelf positions: inner, mid, outer 
the crest and flat of mid- and outer-shelf reef habitats. The differences between the habitats increased across the shelf, being limited on the inner-shelf reefs and marked on outer-shelf reefs. The cover of damselfish territory was generally low across both northern and central inner- $(0.1-4.7 \%)$ and mid-shelf $(0.3-10.7 \%)$ reef habitats. On northern outer-shelf reefs, the back reef and reef crest had the highest cover of damselfish territory, 26.9 and $14.1 \%$ respectively. In contrast, damselfish territories only accounted for $0.8-5.7 \%$ of the benthic substrata across all central outer-shelf habitats. Further details of the EAM, sand/rubble and damselfish territories are provided in Fig. A1 in Appendix 1.

\section{Herbivore distributions}

Total herbivore biomass increased considerably across the shelf in both regions of the GBR, ranging from $0.8-7.9 \mathrm{~kg}$ (per $100 \mathrm{~m}^{2}$ ) on the inner shelf to $5.0-31.7 \mathrm{~kg}$ on the outer shelf (Fig. 3d). Within each shelf location, the highest biomass of herbivorous fishes typically occurred on the reef crest, while back reef and reef slope habitats of the outer-shelf and inner- and mid-shelf back reef and reef flat habitats exhibited the lowest total biomass of herbivorous fishes (Fig. 3d). Patterns in herbivore distribution were generally congruent between the northern and central regions of the GBR, with the exception of the outershelf back reef and mid-shelf reef crest and slope habitats, where biomass was markedly higher within the central region (Fig. 3d).

\section{Correlations: herbivore biomass versus macroalgal cover}

There was a significant negative relationship between macroalgal cover and total herbivorous fish biomass $(\mathrm{r}=-0.361, \mathrm{n}=44, \mathrm{p}=0.016)$, but no significant correlation was found between macroalgal browser biomass and macroalgal cover $(\mathrm{r}=-0.137, \mathrm{n}=44, \mathrm{p}=$ 0.377 ). The relationships are given in Fig. A2 in Appendix 1. The non-significant relationships between benthic community composition and both total herbivore biomass and macroalgal browser biomass are also presented in Fig. A3 in Appendix 1.

\section{DISCUSSION}

There were marked differences in the benthic community structure of the GBR across all spatial scales examined, although northern and central regions exhibited consistent similarities in cross-shelf patterns. In both re- gions of the GBR, the dominant cross-shelf patterns in benthic composition were: (1) a high cover of macroalgae on inner-shelf reef habitats (mean $=42.9 \%$ ), consisting predominantly of Sargassum, Padina and Turbinaria, and very low percentages of macroalgae on mid- and outer-shelf reef habitats (mean $=3.7 \%$ ), consisting only of Chlorophyta (Caulerpa, Halimeda and Chlorodesmis); (2) an approximately 7 -fold increase in the cover of CCA between inner- and outer-shelf reef habitats; and (3) an increase in live scleractinian coral cover across the shelf, with mid- and outer-shelf reef habitats averaging 28.0 and $31.0 \%$ respectively, compared to $18.5 \%$ on innershelf reef habitats. Our data suggest that there are currently 2 markedly different reef 'systems' operating on the GBR, inner-shelf reefs versus mid- and outer-shelf reefs, where each 'system' is characterized by a distinctive benthic composition. These cross-shelf patterns in macroalgal cover appear to be correlated with estimates of total herbivore biomass.

\section{Distribution of macroalgae on the GBR}

The cross-shelf variation in the characteristics of reefs within the GBR has been well documented, especially in relation to benthic composition, faunal assemblages, environmental variables and ecosystem processes (e.g. Done 1982, Bellwood \& Wainwright 2001, Fabricius \& De'ath 2001, Hoey \& Bellwood 2008). However, the separation of inner- from mid- and outer-shelf reefs, particularly in relation to macroalgal cover, is marked and highlights the extent of this division. This raises the question: Why do the inshore reefs of the GBR have such a high abundance of macroalgae? This question has 2 components: When did this pattern arise, and how is it maintained? Given the lack of historical evidence for changes in macroalgal cover on the GBR, the origin of this pattern is difficult to establish. However, one of the key remaining questions is: What maintains this pattern today? If we understand this component, we may also be in a position to better evaluate the factors that may have shaped the history of macroalgae on the GBR.

Macroalgae are often associated with degraded reef systems (Done 1992, Hughes 1994, Bellwood et al. 2004). Typically, reduced herbivory and/or eutrophication have been shown to be influential in structuring benthic communities and driving phase shifts on coral reefs (e.g. Smith et al. 1981, Hughes et al. 2003, 2007, Littler et al. 2006, Mumby et al. 2006). For example, many Caribbean reefs have undergone a phase shift from coral to macroalgal dominance (consisting of Sargassum, Lobophora, Dictyota and Halimeda), which became apparent after the region-wide mass mortality of the herbivorous echinoid Diadema antillarum 
(Hughes 1994). Prior to the die-off, historical overfishing and physical damage by hurricanes greatly reduced the resilience of some Caribbean reefs and facilitated macroalgal colonization (Hughes 1994, Pandolfi et al. 2003). Similarly, the reefs of Kaneohe Bay, Hawaii, underwent a phase shift to macroalgal dominance, although in this location, live coral cover was reduced by eutrophication, caused by a combination of sewage pollution and terrestrial run-off (Smith et al. 1981). Whilst this shift to macroalgal dominance was largely attributed to increased eutrophication within Kaneohe Bay, the main Hawaiian Islands have experienced extensive overfishing (Friedlander \& DeMartini 2002), suggesting that a reduction in herbivory may have also contributed to the shift to macroalgal dominance. Indeed, Friedlander et al. (2007) found a strong negative correlation between macroalgal cover and herbivore biomass within Hawaiian reefs.

Based on macroalgal transplants, McCook (1996) concluded that herbivory, rather than water quality, was the dominant factor influencing the cross-shelf distribution of macroalgae (Sargassum) in the central GBR. More recently, Hughes et al. (2007) demonstrated the importance of herbivorous fishes in controlling algal abundance and preventing phase shifts on inner-shelf reefs, using a long-term herbivore exclusion experiment. This experiment was conducted after a large-scale coral bleaching event on the GBR and demonstrated that, in areas where large herbivorous fishes were present, macroalgal abundances remained low and coral populations were able to recover. However, in areas where large herbivorous fishes were excluded, the cover of macroalgae (predominantly Sargassum) increased dramatically, leading to a decrease in coral recruitment, fecundity and survival (Hughes et al. 2007). Such evidence again suggests that the relatively high abundance of macroalgae on some innershelf reefs is primarily a reflection of cross-shelf variation in herbivory, rather than a consequence of increased inshore nutrient availability.

In line with experimental evidence (e.g. McCook 1996, Hughes et al. 2007), we found a significant negative cross-shelf relationship between estimates of observed total herbivore biomass and macroalgal cover on the GBR. However, a significant correlation does not equate to causation, and one must be cautious when interpreting these results. Unlike Caribbean (e.g. Williams \& Polunin 2001, Mumby et al. 2006) and Hawaiian systems (e.g. Friedlander et al. 2007), where clear negative relationships between macroalgal cover and herbivore biomass have been documented, associations on the GBR appear to be much more complex. This is exemplified by mid-shelf reef habitats where, surprisingly, both macroalgal cover and estimates of observed total herbivore biomass were generally low.
Moreover, we found no significant correlation between estimates of observed macroalgal browser biomass and macroalgal cover across the GBR. This result may be partially a limitation of visual censuses, as recent evidence suggests that while visual censuses are useful for quantifying herbivore species that prevent macroalgal establishment, they may miss an important number of species that remove adult macroalgae (e.g. some rabbitfish and batfish species; Bellwood et al. 2006, Fox \& Bellwood 2008). The question remains, therefore, as to whether the distribution of macroalgae is primarily a result of species that prevent macroalgal growth or of those that remove adult macroalgae (cf. Bellwood et al. 2006).

In addition to herbivory, variation in water quality may also be an important contributing factor affecting gradients in macroalgal cover on the GBR. Over the last century, there has been a substantial increase in the terrestrial run-off of both nutrients and sediments into the coastal regions of the GBR (McCulloch et al. 2003, McKergow et al. 2005). While there has been some indication that the abundance of macroalgae has increased over time at a few inshore locations on the GBR (Done et al. 2007), it is still unknown whether 'fleshy' macroalgal-dominated inner-shelf reefs represent a 'natural' state or are a preliminary indicator of a localized phase shift (McCook et al. 1997). Since macroalgae are abundant on inshore reefs in both the remote northern and more populated central regions of the GBR, it may suggest that macroalgal-dominated inner-shelf reefs are a relatively widespread condition that reflects a post-European settlement GBR configuration with the associated increase in sediments and nutrients. Although there is no history of significant harvesting of herbivorous fishes on the GBR, other herbivores, such as turtles and dugongs, have been directly and indirectly exploited for many years, and their declines may have contributed to an expansion of macroalgae (Bellwood et al. 2006). Nevertheless, the flora of inner-shelf reefs has probably always been different to that of offshore reefs due to the close proximity of natural terrestrial influences. Changes may therefore manifest more clearly in the abundance of, rather than the presence or absence of, macroalgae. Regardless of this history, the extensive range of inshore reefs with high macroalgal cover presents a significant reservoir or source of algal fragments and spores for macroalgal colonization, and could, under changing circumstances, present a threat to the persistence of coral-dominated systems on the GBR (Hughes et al. 2005). Significant long-distance dispersal and establishment of Turbinaria has been documented in French Polynesia (Martinez et al. 2007), and the expansion of macroalgae across the GBR remains a distinct possibility. 
Despite widespread perceptions, a high abundance of macroalgae on coral reefs may not always represent a degraded state, as large abundances can also occur in relatively undisturbed reef systems. For example, macroalgae (Microdictyon setchellianum, Chlorophyta) occupy up to $29 \%$ of the benthos of some back reef and lagoonal habitats of the Northwestern Hawaiian Islands (Vroom et al. 2005). These reefs are isolated and experience very little direct anthropogenic disturbance (Vroom et al. 2005). However, these high macroalgal abundances may be related to the proximity of these reefs to subtropical environments, as similar patterns are seen on the subtropical reefs of Lord Howe Island, the world's most southern coral reef. (Lord Howe Island also exhibits relatively high macroalgal cover [Harriott \& Banks 2002], despite limited anthropogenic disturbance.) Overall, it appears that macroalgae may be normal components of some coral reef benthic communities, and therefore one needs to be careful when identifying degraded reefs based solely on current macroalgal abundance: the critical element is in documenting a change in macroalgal abundance.

\section{Non-macroalgal benthic substrata}

In both the northern and central GBR, the cover of CCA was low on most inner-shelf reef habitats, with cover increasing dramatically on mid-shelf habitats in the central GBR and on outer-shelf habitats in the northern GBR. Fabricius \& De'ath (2001) also found a substantial cross-shelf increase in the cover of CCA, where cover gradually increased from inner- to outershelf reef habitats. The high cover of CCA in both northern and central outer-shelf reef habitats may be influenced by the sedimentary environment, where increased sediment deposition on inshore reefs may reduce both recruitment and photosynthetic capabilities (Fabricius \& De'ath 2001). Variation in grazing intensity by herbivorous reef fishes may also influence the crossshelf distribution of CCA, as these algae are considered to be highly resistant to grazing (Steneck 1986). However, Hoey \& Bellwood (2008) estimated that scarid grazing rates were highest on inner-shelf reefs, which suggests that high sediment loads may be more important than grazing in limiting CCA in these locations.

The cover of live scleractinian coral was generally the greatest on mid- and outer-shelf reef habitats, a pattern previously described by Done (1982). Within each reef, the cover increased considerably from the back reef to reef slope. Both scleractinian corals and CCA are capable of living in areas of high wave energy (Steneck 1986, Madin \& Connolly 2006). Wave energy, which is the greatest on the reef crest (Fulton
\& Bellwood 2005), decreases considerably from outerto inner-shelf reefs (Bellwood \& Wainwright 2001) and is probably a significant driving factor in the crossshelf and within-reef distribution of corals and CCA.

The cover of EAM did not vary markedly among shelf locations, and was generally greatest in back reef and reef flat habitats. This is a common trend in the distribution of EAM, particularly within reef flat habitats, where the cover of epilithic algae is often the greatest (e.g. Klumpp \& McKinnon 1992). Likewise, there was no clear trend in the cover of sand/rubble across the continental shelf, although cover was generally greatest on the back reef and slope habitats of mid- and outer-shelf reefs. This may be most readily attributed to wave and current action, as hydrodynamic forces transport mobile substrata, such as sediment, from areas of high wave energy (e.g. reef crest) to the more sheltered reef habitats (e.g. back reef) (Fulton \& Bellwood 2005).

One final caveat must be noted: the benthic surveys did not explore temporal variation. Some substrata, particularly macroalgae, display strong seasonal changes in abundance. Sargassum, for example, is generally more abundant in the warmer months of December to April, and can decrease considerably in winter (e.g. Martin-Smith 1993). The close similarities between our northern and central surveys, despite being undertaken at different times of the year, probably reflect limited changes in the cover of macroalgae. Greater differences between regions may have been recorded if biomass rather than percent cover was documented.

In summary, the inshore reefs of the GBR differ considerably from mid- and outer-shelf reefs, with the high proportion of macroalgae on the inner-shelf being the dominant distinguishing feature. Although herbivory has been reported to be a key mechanism driving cross-shelf variation in macroalgal cover, the relationship does not appear to be a simple one. Macroalgal cover was correlated with estimated total herbivore biomass, but not with macroalgal browsing fish biomass. It is now clear that we need to move beyond documenting patterns and correlations to understand the mechanistic processes that underpin these patterns. With this knowledge, we may begin to understand how these patterns arose, are maintained and how they will change in the face of global warming.

Acknowledgements. We thank the staff of Orpheus and Lizard Island research stations for field support; A. Barnett, R. Fox, M. Depczynski and C. Fulton for assistance with data collection; colleagues in the Centre of Excellence for helpful discussions; and 3 anonymous reviewers for helpful comments on the manuscript. Financial support was provided by an Ian Potter Foundation doctoral fellowship (A.S.H.), the Australian Research Council and the Great Barrier Reef Marine Park Authority (D.R.B.). 


\section{LITERATURE CITED}

Bellwood DR (1995) Carbonate transport and within-reef patterns of bioerosion and sediment release by parrotfishes (family Scaridae) on the Great Barrier Reef. Mar Ecol Prog Ser 117:127-136

Bellwood DR, Wainwright PC (2001) Locomotion in labrid fishes: implications for habitat use and cross-shelf biogeography on the Great Barrier Reef. Coral Reefs 20: 139-150

Bellwood DR, Hughes TP, Folke C, Nyström M (2004) Confronting the coral reef crisis. Nature 429:827-833

Bellwood DR, Hughes TP, Hoey AS (2006) Sleeping functional group drives coral-reef recovery. Curr Biol 16:2434-2439

Burkepile DE, Hay ME (2006) Herbivore vs. nutrient control of marine primary producers: context-dependent effects. Ecology 87:3128-3139

Choat JH, Clements KD, Robbins WD (2002) The trophic status of herbivorous fishes on coral reefs. 1. Dietary analyses. Mar Biol 140:613-623

Cvitanovic C, Bellwood DR (2009) Local variation in herbivore feeding activity on an inshore reef of the Great Barrier Reef. Coral Reefs (in press)

> Dinesen ZD (1983) Patterns in the distribution of soft corals across the central Great Barrier Reef. Coral Reefs 1: $229-236$

Done TJ (1982) Patterns in the distribution of coral communities across the central Great Barrier Reef. Coral Reefs 1: 95-107

> Done TJ (1992) Phase shifts in coral reef communities and their ecological significance. Hydrobiologia 247:121-132

$>$ Done T, Turak E, Wakeford M, DeVantier L, McDonald A, Fisk D (2007) Decadal changes in turbid-water coral communities at Pandora Reef: loss of resilience or too soon to tell? Coral Reefs 26:789-805

Fabricius K, De'ath G (2001) Environmental factors associated with the spatial distribution of crustose coralline algae on the Great Barrier Reef. Coral Reefs 19:303-309

$>$ Fox RJ, Bellwood DR (2008) Remote video bioassays reveal the potential feeding impact of the rabbitfish Siganus canaliculatus (f: Siganidae) on an inner-shelf reef of the Great Barrier Reef. Coral Reefs 27:605-615

Friedlander AM, DeMartini EE (2002) Contrast in density, size, and biomass of reef fishes between the northwestern and the main Hawaiian Islands: the effects of fishing down apex predators. Mar Ecol Prog Ser 230:253-264

Friedlander AM, Brown E, Monaco ME (2007) Defining reef fish habitat utilization patterns in Hawaii: comparisons between marine protected areas and areas open to fishing. Mar Ecol Prog Ser 351:221-233

Fulton CJ, Bellwood DR (2005) Wave-induced water motion and the functional implications for coral reef fish assemblages. Limnol Oceanogr 50:255-264

Gardner TA, Cote IM, Gill JA, Grant A, Watkinson AR (2003) Long-term region-wide declines in Caribbean corals. Science 301:958-960

> Graham NAJ, Wilson SK, Jennings S, Polunin NVC, Bijoux JP, Robinson J (2006) Dynamic fragility of oceanic coral reef ecosystems. Proc Natl Acad Sci USA 103:8425-8429

Harriott VJ, Banks SA (2002) Latitudinal variation in coral communities in eastern Australia: a qualitative biophysical model of factors regulating coral reefs. Coral Reefs 21: 83-94

$>$ Hoey AS, Bellwood DR (2008) Cross-shelf variation in the role of parrotfishes on the Great Barrier Reef. Coral Reefs 27: $37-47$

Hughes TP (1994) Catastrophes, phase shifts, and large-scale degradation of a Caribbean coral reef. Science 265: $1547-1551$

Hughes TP, Baird AH, Bellwood DR, Card M and others (2003) Climate change, human impacts, and the resilience of coral reefs. Science 301:929-933

> Hughes TP, Bellwood DR, Folke C, Steneck RS, Wilson J (2005) New paradigms for supporting the resilience of marine ecosystems. Trends Ecol Evol 20:380-386

Hughes TP, Rodrigues MJ, Bellwood DR, Ceccarelli D and others (2007) Phase shifts, herbivory, and the resilience of coral reefs to climate change. Curr Biol 17:360-365

Hunter CL, Evans CW (1995) Coral reefs in Kaneohe Bay, Hawaii: two centuries of western influence and two decades of data. Bull Mar Sci 57:501-515

Klumpp DW, McKinnon AD (1992) Community structure, biomass and productivity of epilithic algal communities on the Great Barrier Reef: dynamics at different spatial scales. Mar Ecol Prog Ser 86:77-89

Kulbicki M, Mou Tham G, Thollot P, Wantiez L (1993) Lengthweight relationships of fish from the lagoon of New Caledonia. Naga 16(2):26-30

Kulbicki M, Guillemot N, Amand M (2005) A general approach to length-weight relationships for New Caledonian lagoon fishes. Cybium 29:235-252

> Ledlie MH, Graham NAJ, Bythell JC, Wilson SK, Jennings S, Polunin NVC, Hardcastle J (2007) Phase shifts and the role of herbivory in the resilience of coral reefs. Coral Reefs 26: 641-653

> Littler MM, Littler DS, Brooks BL (2006) Harmful algae on tropical coral reefs: bottom-up eutrophication and topdown herbivory. Harmful Algae 5:565-585

> Madin JS, Connolly SR (2006) Ecological consequences of major hydrodynamic disturbances on coral reefs. Nature 444:477-480

Martinez E, Maamaatuaiahutapu K, Payri C, Ganachaud A (2007) Turbinaria ornata invasion in the Tuamotu Archipelago, French Polynesia: ocean drift connectivity. Coral Reefs 26:79-86

Martin-Smith KM (1993) The phenology of four species of Sargassum at Magnetic Island, Australia. Bot Mar 36: 327-334

McClanahan TR, Muthiga NA, Mangi S (2001) Coral and algal changes after the 1998 coral bleaching: interaction with reef management and herbivores on Kenyan reefs. Coral Reefs 19:380-391

- McCook LJ (1996) Effects of herbivores and water quality on Sargassum distribution on the central Great Barrier Reef: cross-shelf transplants. Mar Ecol Prog Ser 139:179-192

McCook LJ (1999) Macroalgae, nutrients and phase shifts on coral reefs: scientific issues and management consequences for the Great Barrier Reef. Coral Reefs 18: 357-367

McCook LJ, Price IR, Klumpp DW (1997) Macroalgae on the GBR: causes or consequences, indicators or models of reef degradation? Proc 8th Int Coral Reef Symp 2:1851-1856

> McCulloch M, Fallon S, Wyndham T, Hendy E, Lough J, Barnes D (2003) Coral record of increased sediment flux to the inner Great Barrier Reef since European settlement. Nature 421:727-730

McKergow LA, Prosser IP, Hughes AO, Brodie J (2005) Regional scale nutrient modeling: exports to the Great Barrier Reef World Heritage Area. Mar Pollut Bull 51: 186-199

Mumby PJ, Dahlgren CP, Harborne AR, Kappel CV and others (2006) Fishing, trophic cascades, and the process of grazing on coral reefs. Science 311:98-101

Pandolfi JM, Bradbury RH, Sala E, Hughes TP and others 
(2003) Global trajectories of the long-term decline of coral reef ecosystems. Science 301:955-958

Randall JE, Allen GR, Steene RC (1997) Fishes of the Great Barrier Reef and Coral Sea. Crawford House Publishing, Bathurst

Shulman MJ, Robertson DR (1996) Changes in the coral reefs of San Blas, Caribbean Panama: 1983-1990. Coral Reefs 15:231-236

Smith SV, Kimmerer WJ, Laws EA, Brock RE, Walsh TW (1981) Kaneohe Bay sewage diversion experiment: perspectives on ecosystem responses to nutritional perturbation. Pac Sci 35:279-395

Steneck RS (1986) The ecology of coralline algal crusts: convergent patterns and adaptive strategies. Annu Rev Ecol Syst 17:273-303

Steneck RS (1988) Herbivory on coral reefs: a synthesis. Proc 6th Int Coral Reef Symp 1:37-49

Editorial responsibility: Charles Birkeland, Honolulu, Hawaii, USA
Vroom PS, Page KN, Peyton KA, Kukea-Shultz JK (2005) Spatial heterogeneity of benthic community assemblages with an emphasis on reef algae at French Frigate Shoals, Northwestern Hawaiian Islands. Coral Reefs 24:574-581

Vroom PS, Page KN, Kenyon JC, Brainard RE (2006) Algaedominated reefs: numerous reports suggest that reefs must be dominated by coral to be healthy, but many thriving reefs depend more on algae. Am Sci 94:430-437

Wilkinson CR (ed) (2004) Status of coral reefs of the world: 2004. Australian Institute of Marine Science, Cape Ferguson and Dampier

Williams ID, Polunin NVC (2001) Large-scale associations between macroalgal cover and grazer biomass on middepth reefs in the Caribbean. Coral Reefs 19:358-366

Wilson S, Bellwood DR, Choat JH, Furnas M (2003) Detritus in coral reef ecosystems and its use by coral reef fishes. Oceanogr Mar Biol Annu Rev 41:279-309

Submitted: July 29, 2008; Accepted: October 20, 2008 Proofs received from author(s): January 28, 2009 